\title{
Craniofacial Pain and Motor Function: Pathogenesis, Clinical Correlates, AND IMPLICATIONS
}

\author{
C.S. Stohler \\ Department of Biologic and Materials Sciences, and Center for Human Growth and Development, 1011 N. University, The University of Michigan, Ann Arbor, Michigan 48109-1078, USA
}

\begin{abstract}
Many structural, behavioral, and pharmacological interventions imply that favorable treatment effects in musculoskeletal pain states are mediated through the correction of muscle function. The common theme of these interventions is captured in the popular idea that structural or psychological factors cause muscle hyperactivity, muscle overwork, muscle fatigue, and ultimately pain. Although symptoms and signs of motor dysfunction can sometimes be explained by changes in structure, there is strong evidence that they can also be caused by pain. This new understanding has resulted in a better appreciation of the pathogenesis of symptoms and signs of the musculoskeletal pain conditions, including the sequence of events that leads to the development of motor dysfunction. With the improved understanding of the relationship between pain and motor function, including the inappropriateness of many clinical assumptions, a new literature emerges that opens the door to exciting therapeutic opportunities. Novel treatments are expected to have a profound impact on the care of musculoskeletal pain and its effect on motor function in the not-too-distant future.
\end{abstract}

Key words. Muscle pain, muscle activity, muscle tone, temporomandibular disorders, myofascial pain, fibromyalgia.

\section{Introduction}

This is review provides readers with an analysis of newer data that challenge the didactic and clinical dogma of musculoskeletal craniofacial pain. It examines the extent to which newer findings support the traditional thinking or, alternatively, promote the formulation of promising treatment targets for patients with persistent craniofacial pain and mandibular dysfunction.

Many of the traditional theories that are used to explain the clinical phenomenon of musculoskeletal pain involve nebulous descriptions like muscle hyperactivity, muscle spasm, and overwork (Ramfjord and Ash, 1983; Solnit and Curnutte, 1988). According to the best available studies involving craniofacial muscle, treatments that are based on the rationale of correcting muscle hyperactivity, muscle spasm, and overwork show remarkably high success rates, ranging from 70 to $90 \%$ (Greene and Laskin, 1974, 1983; Carraro and Caffesse, 1978; Dohrmann and Laskin, 1978; Nel, 1978; Heloe and Heiberg, 1980). However, clinically observable success cannot be used in support of the validity of the hyperactivity, muscle spasm, and overwork' theory. From a scientific point of view, other modes of action cannot be excluded.

The fact that a wide range of structural, behavioral, and pharmacological interventions produces similar success rates puts the specificity of their respective treat- ment targets into question. Alternatively, unspecific treatment effects and/or patients' features that increase the likelihood of a favorable outcome should be used as an explanation for success. It is important to recognize that the 'hyperactivity, muscle spasm, and overwork' construct does not provide justice for the worst-case scenario of persistent and disabling motor function, encountered by 10 to $30 \%$ of subjects for whom a favorable treatment response is not achieved. If nothing works, the 'muscle hyperactivity, muscle spasm, and overwork' construct provides no other explanation than to blame the patient for not being able to adapt despite the skilled work being provided to him or her.

Regardless of the established clinical mores and strong, often emotionally charged views held by many working in the field, new understanding is not likely to emerge if historical data are sought to answer unresolved questions. Instead, scientific advances are needed to support the development of therapies that take into account the heterogeneity in disease manifestation, treatment need, and response. A case can also be made for re-examining the validity of the theories that are being used to justify the available treatments.

Painful jaw motor conditions represent one form of several motor disorders affecting the craniofacial system. Movement disorders including forms of oral-facial hyperkinesia, hypokinesia, dyskinesia, bradykinesia, dystonia, myoclonus, and tics are beyond the scope of this review. 
Also, mechanical impediments that cause obstruction to mandibular movement will also not be discussed in this article. While newer studies provide convincing evidence that women are more likely to be affected by persistent craniofacial pain than men, the limited information available on gender-specific aspects of motor function does not allow for any systematic consideration of this matter at this time.

\section{Problems Encountered by Clinical Research}

Because mandibular dysfunction and pain are expressed simultaneously, a complete understanding of the nature of the link between these clinical features cannot be obtained from the study of clinical material. Although the study of clinical cases provides valuable data of a phenomenological nature, observations of pain and motor dysfunction in clinical material are also confounded by significant case heterogeneity that is rarely acknowledged. This heterogeneity in the clinical material is reflected in differences in etiology, pain distribution, mood, gender effects, impact, and previous treatment effects. For many years, the craniofacial musculoskeletal conditions were lumped under the term of "TMJ dysfunction" or a similar designation, with clinical research rarely acknowledging the existing case diversity. While pain, with few exceptions, is a central feature of these conditions, different etiologies may be in effect. On the other hand, shared disease and protective-adaptive processes appear to be responsible for the overlapping symptoms and signs of these musculoskeletal pain conditions (Lund and Sessle, 1994).

Important in guiding research and the conceptual understanding were recent attempts to produce a logical taxonomy for the temporomandibular (TM) disorders (Dworkin and LeResche, 1992). From a phenomenological point of view, three major diagnostic subsets are distinguished: (1) the masticatory muscle disorders, (2) disk interference disorders, and (3) the TM joint arthritides. This distinction appears to be justified by discrete differences in presentation and perceived differences in the clinical course between subsets. From a research perspective, there is concern about the delineation of these subsets including conditions like headaches. The fact that diagnostic assignments to subsets of TM disorders are often not stable over time (Huggins et al., 1996) constitutes another concern.

Matters are further complicated by factors that are often overlooked in clinical studies. The spatial pain distribution, pain intensity, temporal aspects of pain, and mood are factors that likely affect motor function. It is essential to distinguish between patients with recently acquired pain from patients with long-established persistent pain. Individual pain distribution of musculo- skeletal craniofacial pain falls into one of three clusters that consist of (a) the region involving the trigeminal dermatomes, (b) the trigeminal and upper cervical dermatomes, and (c) pain sites in addition to those listed above (Turp et al., 1998a). Because patients with TM disorders and widespread pain were least tolerant of pain experimentally induced by cutaneous electrical stimulation over the masseter muscles (Hagberg, 1991), differences in peripheral mechanisms and/or central neural processing between subjects with different pain distributions should be expected.

Regardless of the diagnostic subset, the worst scenario consists of cases with chronic disabling pain and dysfunction. For milder and episodic forms, the impact of the condition constitutes more a nuisance than a burden. Consequently, the treatment need of mild and episodic forms is minimal to none. On the other hand, many patients with persistent pain continue to suffer and, in the search for cures, become desperate for explanations about what has happened to their lives. Analysis of the treatment-seeking patterns of 206 consecutive patients of a university-based tertiary care clinic showed that, on average, 4.9 providers from 44 different health care disciplines were consulted prior to the referral. About $28 \%$ of patients were dissatisfied or very dissatisfied with the care they received, making it clear that much needs to be done before the population of persistent sufferers is served satisfactorily (Turp et al., 1998b).

Persistent pain is also accompanied, to various degrees, by functional limitations and restrictions in daily activities (Hawley and Wolfe, 1991; Von Korff et al., 1992; Hazard et al., 1994; Tesio et al., 1997). It is not surprising that for patients with TM disorders, the bodily pain distribution contributes to the level of disability. Cases with pain restricted to the head and neck show lower disability scores than presentations involving widespread pain (Turp et al., 1997). Various levels of suffering, frustration, decreased self-esteem, depressive pre-occupation, increased use of medications and health-care services, reduced patient autonomy, high disability-related expenditures, loss of productivity, and reduced quality of life further emphasize the heterogeneity among clinical cases (Turk, 1996).

\section{Explanatory Models}

For almost one century, abnormal muscle function leading to muscle overwork and muscle fatigue has been regarded as a cause of pain (Hough, 1902; Asmussen, 1956; Abraham, 1977; Howell et al., 1985). This basic idea has been adopted by a variety of etiological constructs that view abnormalities in either structure, posture, movement, stress, or other psychological disturbances as cause for muscles to work harder so that they become 

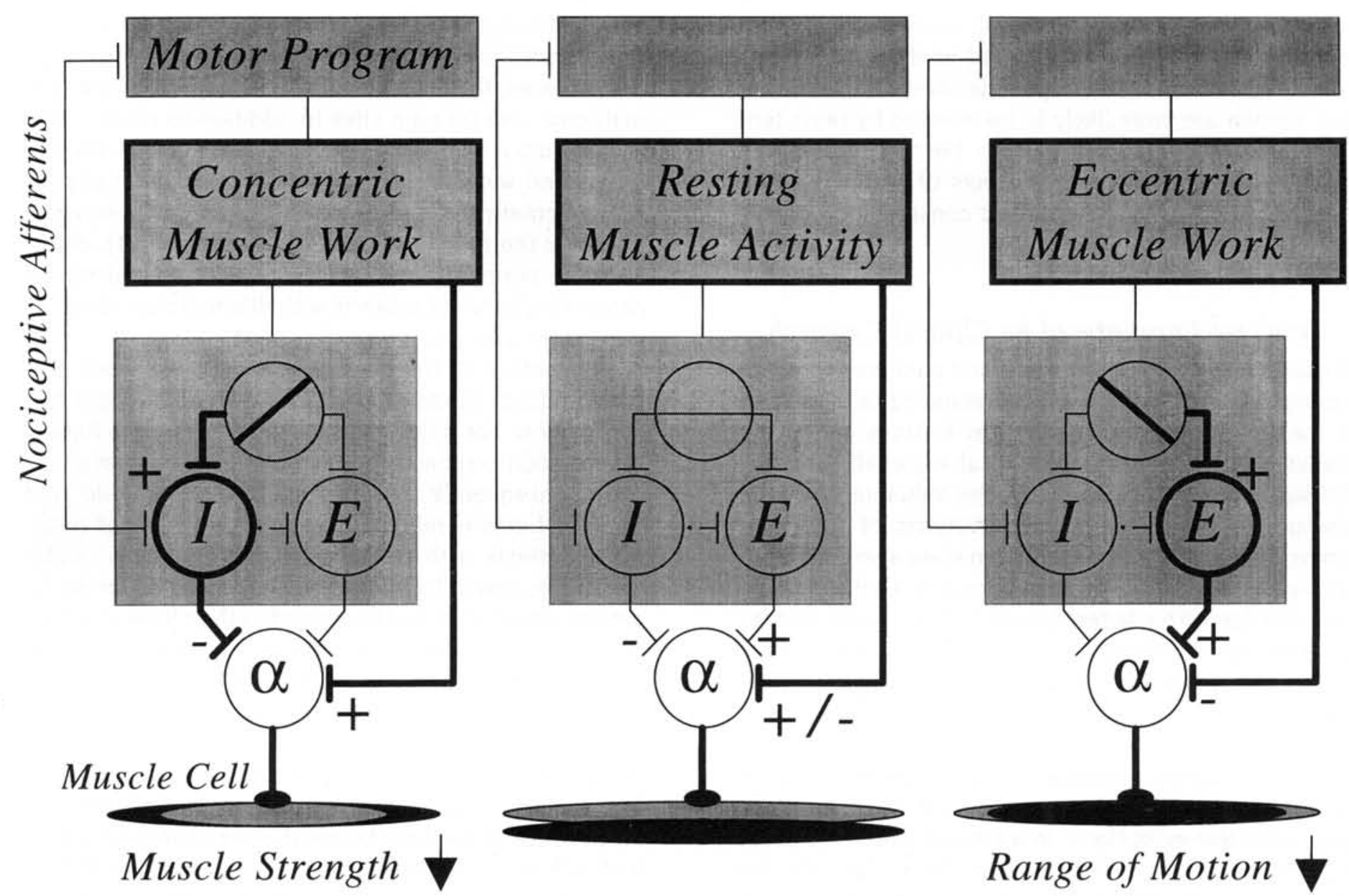

Figure 1. Principal features of the Pain-Adaptation Model (modified from Lund et al., 1991). In the presence of noxious afferent input to the motor program and brainstem interneurons, the model predicts a decrease in muscle strength in concentric muscle work and reduced range of motion due to co-contraction of extensors during eccentric muscle work. In the absence of movement, no significant effect on $\alpha$ motoneurons is expected. Key elements in the described mechanisms are excitatory and inhibitory interneurons that act on the $\alpha$-motoneurons. I, $\mathrm{E}=$ inhibitory, excitatory premotor nociceptive interneurons; $\alpha=\alpha$-motoneurons; + refers to excitation, - to inhibition.

fatigued. Many disciplines have adopted this basic construct to justify their treatment. As far as dentistry is concerned, the need to change the dental occlusion was considered essential for the elimination of pain (Solnit and Curnutte, 1988). When the idea of muscle overwork and fatigue was combined with that of pain causing muscle hyperactivity or muscle spasms, the popular Vicious Cycle Theory (also referred to as the "pain-spasm-pain theory") came into existence to account for the persistence of pain through a mutually reinforcing, vicious link between pain and muscle hyperactivity (Travell et al., 1942).

Despite questions of its validity (see below), the continuing popularity of the Vicious Cycle Theory is believed to be due to the fact that treatment foci are conveniently chosen and justification for re-treatment is readily offered in situations in which the problem persists. As far as the communication with patients is con- cerned, the reasons for treatment, treatment targets, and additional treatment needs are easily explained and readily understood. The theory is convenient insofar as it provides an explanation for both favorable and unfavorable treatment outcomes. The favorable treatment response is explained by the correction of either the structural or psychological disturbance. Alternatively, treatment failure occurs due to the provider's inability to correct the abnormality or the patient's inability to adapt to the corrected situation. Escalation of treatment is justified by the need to break the vicious cycle.

In an attempt to resolve matters of incompatibility of the pain-spasm-pain theory with clinical facts, "overlapping referred pain patterns of trigger points" have been proposed to explain the absence of electromyographic (EMG) evidence in support of the theory's key assumption. The revised thinking is based on the idea that painful muscle conditions are closely associated with 
myofascial trigger points and palpable taut bands. An important aspect of the revised theory consists of the proponents' claim that marked reduction in the tenseness of the taut bands occurs after the effective inactivation of a trigger point, because an inactivated taut band supposedly restores normal function to the sarcoplasmic reticulum (Simons and Mense, 1998). However, given the unreliable assessment of taut bands (Wolfe et al., 1992), the usefulness of this recent revision of the pain-spasm-pain theory from both a research and management perspective appears problematic. This is further supported by the low inter-rater reliability of trigger point assessments in the lower back (Nice et al., 1992) in a region that is unquestionably more favorable for tissue assessment than the craniofacial complex.

Rather than endorsing a specific treatment, the PainAdaptation Model formulated by Lund and co-workers (1991) was supposed to account for all known changes of motor function in situations of pain. For reasons of construct validity, the explanatory model needed to acknowledge that (1) pain has general effects that include changes in posture and facial expressions, (2) motor effects are independent of the type of tissue in which pain arises, (3) reduced agonist muscle output is encountered in concentric (shortening contraction), muscle work, and (4) co-contraction of muscle antagonists occurs during muscle extension (Lund et al., 1991). The principal features of the Pain-Adaptation Model are illustrated in Fig. 1. In the presence of nociceptive input to the motor program and brainstem interneurons, the model predicts a decrease in muscle strength in concentric muscle work and a reduced range of motion and slowing of movement due to antagonistic co-contraction of extensors during eccentric muscle work. In the absence of movement, no significant effect on $\alpha$-motoneurons is expected. Key elements in this hypothetical model are excitatory and inhibitory interneurons that act on $\alpha$-motoneurons. An elegant and detailed presentation of the Pain-Adaptation Model is offered in a recently published text (Lund and Sessle, 1994). Unlike the Vicious Cycle Theory, in which the dysfunction constitutes a maladaptive behavior that is essential to the development of pain, the Pain-Adaptation Model regards painrelated changes in motor function as serving an adaptiveprotective purpose.

While the Vicious Cycle Theory provided a construct for guiding the clinician, the Pain-Adaptation Model was formulated to generate hypotheses and to stimulate research into the relationship between pain and motor function. Based on this perspective, this review will extend the findings of previous critical reviews (Lund et al., 1991, 1993: Lund and Stohler, 1994) with respect to the extent to which research findings are consistent with the key assumptions of the Vicious Cycle Theory or predictions of the Pain-Adaptation Model.

\section{Pain and Postural Muscle Activity}

It is a common experience that heavy, fatiguing, or unaccustomed, particularly eccentric (lengthening contraction), muscle work causes tissue injury and pain. Postexercise muscle soreness (PEMS) represents an example of work-induced damage, and the resulting inflammatory response appears to be different from straight tissue injury (Newham et al., 1983a,b; Jones et al., 1987, 1989; Nosaka and Clarkson, 1996). The suggestion has been made that some forms of bruxism, oral habits, and certain movement disorders, such as spasmodic torticollis or myoclonus, may produce PEMS (Lund et al., 1991, 1995). On the other hand, the observation of seriously worn teeth in the absence of pain suggests that heavy exercise does not inevitably result in pain. Masticatory muscles can adapt to years of physical exercise by becoming resistant to fatigue (Farmand and Rowlerson, 1985). Furthermore, not every pain case will experience an aggravation of pain with exercise. Although the exacerbation of pain with chewing might be expected in myofascial pain patients, pain increases in only about half of subjects; a decrease of pain was reported by about one-third of the study participants (Dao et al., 1994).

Post-exercise muscle soreness represents an interesting model for the study of the relationship between pain and muscle activity, because it allows for measurements in the same subject of both the presence and absence of pain. Within-subject comparisons circumvent the difficulties with the assembly of matched pairs. Contrary to the prediction of the Hyperactivity-Vicious Cycle Theory, increased resting muscle activity is not found in comparisons of measurements before and after heavy exercise that caused soreness (Newham et al., 1983a; Howell et al., 1985; Jones et al., 1987). As far as bruxers are concerned, there is no difference between the resting muscle activity levels in subjects who report pain and those who do not (Sherman, 1985).

Contrary to the popular assumption, the evidence further suggests that other common pain conditions do not exhibit signs of resting or postural muscle hyperactivity. Studies that included age and sex-matched controls question this assumption for chronic lower back pain (Hoyt et al., 1981; Collins et al., 1982; Ahern et al., 1988; Geisser et al., 1995), fibromyalgia (Zidar et al., 1990), and tension-type headache (Sutton and Belar, 1982). Specifically, there is no consistent relationship between pericranial electromyographic (EMG) activity levels and the presence or absence of headache, or the time course of the headache (Schoenen et al., 1991). Mean EMG activity levels that were acquired during exposure to a mental stressor also do not appear to be of any significance for the subsequent development of pain in shoulder, neck, and facial regions (Bansevicius et al., 1997), and the idea that the reduction of paraspinal EMG activity constitutes 
the active ingredient of biofeedback therapy has also been questioned (Nouwen and Bush, 1984).

Regarding the craniofacial complex, the matter is more complicated. Some studies involving subjects with TM disorders found greater resting muscle activities in pain patients than controls (Dahlström et al., 1985; Rugh and Montgomery, 1987). Others were unable to document such differences (Majewski and Gale, 1984; Sherman, 1985). This discrepancy can be explained by confounding factors, such as bruxism and the contamination of the electromyographic record by signals coming from the muscles of facial expression. With the greater prevalence of bruxers among patients with TM disorders than among healthy age- and sex-matched controls, muscle hypertrophy can be offered as an explanation for higher resting activities in pain groups than in controls. Indeed, differences in postural muscle activity between patients with TM disorders and age- and sexmatched controls disappear once the groups are balanced for bruxism (Sherman, 1985).

Besides bruxism, there is a second point to consider. It deals with the function of the muscles of facial expression. Indication of the confounding effects of the muscles of facial expression comes from the fact that the resting muscle activity over the frontalis region is significantly higher in patients with lower back pain than in controls (Collins et al., 1982). However, distant from the muscles of facial expression, such as over-painful trunk or limb muscles, levels of postural activity are not different from control values (Collins et al., 1982; Ahern et al., 1988; Zidar et al., 1990).

As far as the human scalp is concerned, signals from facial muscles have been shown to contaminate the electroencephalogram in experimental jaw muscle pain (Veerasarn and Stohler, 1992). Contrary to our earlier interpretation, we now believe that the platysma muscle was the source of the statistically significant increase in surface EMG activity of $1-2 \mu \mathrm{V}$ over the sternocleidomastoid muscle following the induction of experimental pain (Ashton-Miller et al., 1990). Indeed, innervated by the VIIth nerve, the platysma muscle has long been recognized as a muscle of facial expression (Darwin, 1873). It needs to be emphasized in this context that there are also no published data linking changes in resting muscle activity of less than $1 \%$ of the maximum muscle output to the development of fatigue and pain.

Increases in resting muscle activity similar to those over the sternocleidomastoid muscle were recorded in the face over the masseter and temporalis muscles in experimental masseter pain. However, these increases did not prove to be specific to pain. The resting EMG recorded for subjects during the task of recalling the experience of pain in the head region had almost the same effect, and the two conditions, pain and pain from memory, could not be distinguished on the basis of the EMG record. Increases in surface EMG activity, averaged by subject and recording site, ranged from 0.53 to 0.70 $\mu \mathrm{V}$ for genuine pain and from 0.63 to $0.91 \mu \mathrm{V}$ for imagined pain (Stohler et al., 1996).

There is good evidence that the surface EMG is sensitive to subtle psychomotor effects. Imagining happy or sad events or events of a typical day cause measurable differences in the EMG record of the corrugator muscles, regardless of whether subjects are depressed or not (Oliveau and Willmuth, 1979). Different emotions evoke characteristic facial expression, with pain being one of them (LeResche and Dworkin, 1984; Craig and Patrick, 1985). Indeed, facial expressions have long been recognized to provide important non-verbal cues to signal pain and to request understanding and sympathy (Darwin, 1873). Greater pain affect amplifies the facial features associated with pain (LeResche and Dworkin, 1988).

In summary, published evidence put into question the existence of resting or postural hyperactivity in situations of pain. Therefore, the rationale of treatments that are aimed at pain relief through the reduction of muscle hyperactivity is unsupported. This invalidates the rationale (not necessarily the treatment as such) of most treatments, including occlusal appliances and muscle relaxants, that are offered to patients to "eliminate muscle spasms or muscle hyperactivity". Unlike other parts of the body, the situation in the face is complicated by the fact that small increases in resting EMG activity can be linked to either muscle hypertrophy associated with bruxism or to effects of the muscles of facial expression that lie closely underneath the measurement electrodes.

\section{Pain and Concentric Muscle Work}

During forceful shortening contractions, muscle output in pain is less than in its absence. Support for this statement comes from two lines of evidence that consist of the comparison of the maximum voluntary contraction of pain subjects and (matched) controls, or investigations with subjects in pain or in the pain-free state. The available evidence further suggests that the motor behavior of a muscle in forceful concentric muscle work can be generalized in the sense that findings from the masticatory system are comparable with observations in other parts in the body.

Any finding of reduced muscle strength in pain is difficult to explain by 'muscle hyperactivity'. Attempts to consolidate the observation of reduced maximum output of muscles during concentric work with the Hyperactivity-Vicious Cycle Theory were based on the computation of relative strength (Moller et al., 1984). Relative strength was defined as the fractional effort in 
percent of the functional workload relative to the maximum voluntary contraction of the muscle in question. Because the functional output often represents a greater fraction of the maximum voluntary effort of a muscle in pain than in its absence, findings were interpreted in support of the Hyperactivity-Vicious Cycle Theory. However, alternative interpretations question the validity and usefulness of this mathematical construct.

There appears to be no question that maximum muscle output during forceful concentric muscle work is reduced in the presence of pain. Fibromyalgia patients reach only $64 \%$ of mean control maximum handgrip (Backman et al., 1988 ), or $76 \%$ of the mean maximum voluntary contraction of the adductor pollicis of matched control subjects (Bengtsson et al., 1986b). Neck flexor peak force is significantly lower in the neck pain population compared with controls (Barton and Hayes. 1996). Compared with baseline measurements, a $40 \%$ reduction in muscle strength of the elbow flexors was noted in PEMS (Howell et al., 1993). Decreases in muscle strength were also reported for low back pain (Alston et al., 1966; Thorstensson and Arvidson, 1982). In the lower limb, reduced strengths in the knee extensor muscles of fibromyalgia patients, or hip flexors of osteoarthritis patients, were found when measurements were compared with those from controls (Jacobsen and Danneskiold-Samsoe, 1987). Because ulnar nerve stimulation produced similar force outputs in both fibromyalgia patients and controls, the reduction in muscle strength was attributed to either the lack of motivation due to fear of causing harm or the result of reflex inhibition by nociceptive afferents (Backman et al. 1988). Observations in experimental pain confirm data obtained from pain patients. The torque produced by dorsiflexion of the foot is significantly reduced in the presence of hypertonic saline-induced muscle pain in lower limb muscles when compared with placebo injection in the same location (Graven-Nielsen $t$ t al., 1997).

With respect to concentric muscle work, the
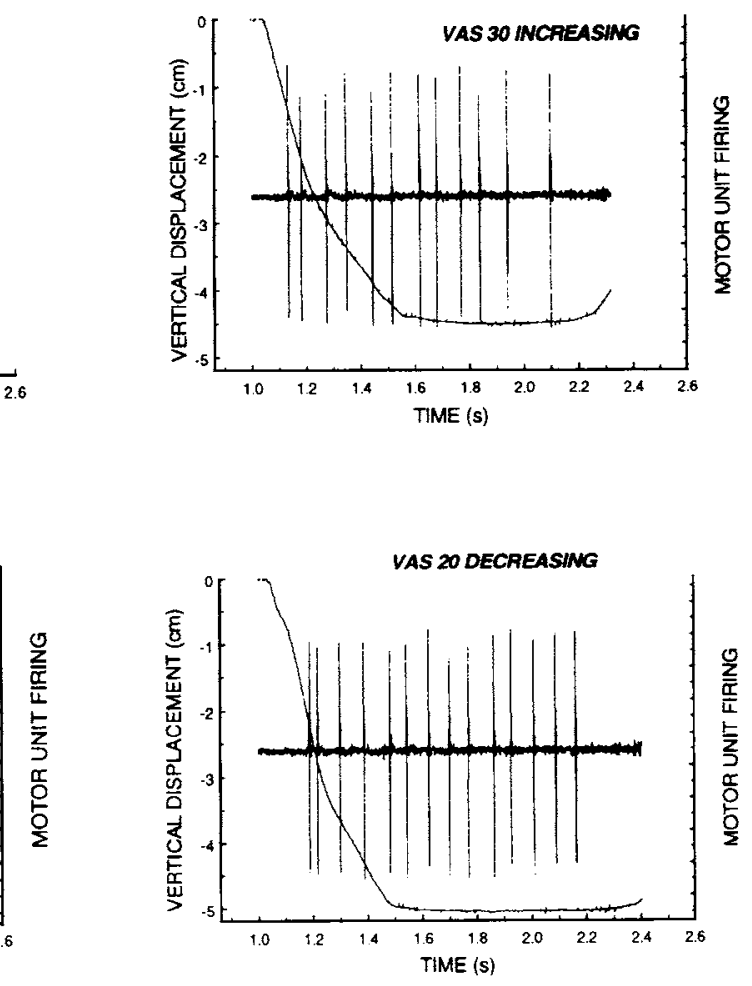

Figure 2. Masseteric motor unit firing during jaw opening in the condition of pain. VAS refers to the subject's pain intensity rating on a scale with endpoints marked "no pain" (0) and "most intense pain imaginable" (100). Note that the maximum voluntary jaw-opening movements became smaller with increasing pain intensities. In parallel, masseteric motor units fired at higher rates with increasing pain intensities, and units that did not fire at lower intensities were recruited at higher pain intensities (unpublished data). 
mechanisms. During the application of heavy pressure on the periosteum of the zygoma, significantly reduced EMG masseter bursts were observed in the jaw-closing phase of fictive mastication, initiated by the electrical stimulation of the corticobulbar tracts in the decerebrate rabbit (Schwartz and Lund, 1995). Similar modifications of fictive mastication were also obtained with the infusion of hypertonic saline into the masseter of decerebrate rabbits at rates that cause pain in human subjects (Schwartz et al., 1993). Given the decerebrate state of the experimental animals, these results support the premise of the brainstem exerting significant control in the modulation of motor function in the presence of noxious input.

Overall, these findings further question the validity and usefulness of earlier mathematical constructs that attempted to consolidate the reduced muscle output during painful concentric muscle work with the Hyperactivity-Vicious Cycle Theory. On the contrary, a useful model should explain the reduced muscle output in painful concentric muscle work rather than attempting to construct evidence of hyperactivity that does not exist in the first place.

\section{Pain and Eccentric Muscle Work}

Contrary to concentric muscle work in pain, studies in humans show a tendency for muscles to become slightly more active during eccentric muscle work. Co-contraction during eccentric work would account for the slowing of movement during muscle extension or the limitation of the range of motion. Because the muscle activity associated with co-contraction is low, it is not easily visualized by surface electromyography given the range of signals, with postural activity being one extreme and maximum voluntary contraction the other. For surface electromyography, it has been suggested that logarithmic amplification is better suited to resolve the functional low and intermediate levels of activity while preserving the occasional high-level response (Stohler et al., 1985b). While the response of eccentric muscle work to pain appears to apply to the masticatory system, neck, trunk, and limbs, confounding effects from the action of muscles of facial expression need to be considered when surface electrodes are applied in the face. To reduce the possibility of signal contamination from the muscles of facial expression or the likelihood of "crosstalk" from neighboring muscle agonists, in-dwelling electromyography should be considered whenever possible.

Statistically significant increases in EMG activity during eccentric muscle work have been reported in clinical studies of lower back pain (de Ceballos et al., 1986; Triano and Schultz, 1987; Ahern et al., 1988), in muscles of the lower limb in saline-induced experimental pain (Graven-Nielsen et al., 1997), and in clinical studies involving TM pain (Moller et al., 1984; Stohler et al., 1985a,
1988). Gait analyses show that decreased extension is significantly associated with increased pain (Hurwitz et al. 1997). Reductions in the range of motion during voluntary movements in hypertonic saline-induced muscle pain mimic those found in TM patients. The amplitudes of the protrusive and lateral excursions are significantly less in pain than during the infusion of a barely uncomfortable control solution or at baseline (Obrez and Stohler, 1996). In experimentally induced pain, significantly smaller vertical and lateral movement amplitudes were found in deliberate unilateral chewing in the condition of pain (Svensson et al., 1996). When computer-controlled infusions of hypertonic saline were used to study the effect of pain intensity on jaw motor function (Zhang et al., 1993), the maximum voluntary jaw-opening movements became smaller with increasing pain intensities In parallel, masseteric motor units fired at higher rates with increasing pain intensities. In addition, motor units that did not fire at lower intensities were recruited at higher pain intensities (Fig. 2). The fact that the recruitment of motor units in eccentric work was seen only at wider mouth openings may explain the absence of visible signs of co-contraction in movements initiated by the electrical stimulation of the corticobulbar tracts in the decerebrate rabbit (Schwartz and Lund, 1995).

There has been the suggestion that co-contraction of a small number of motor units in an otherwise quiescent muscle could produce a situation that is similar to postexercise muscle soreness. Support of the idea of overexertion of low-threshold motor units is limited and consists of the increased occurrence of "ragged-red fibers" in the trapezius of patients with shoulder myalgia (Bengtsson et al., 1986a; Larsson et al., 1988; Lindman et al. 1991). It is possible that focal injury of muscle fibers or connective tissue could add another layer of complexity to the clinical presentation; however, more data are needed to judge the validity and significance of this proposed mechanism.

In summary, several studies that examined the submaximal and maximal range of motion tend to show evidence of antagonistic co-contraction. At first glance, this could be interpreted as evidence of 'muscle hyperactivity'; however, this is neither useful nor does it recognize the depth of current understanding. On the contrary, the argument can be made that the co-contraction of the antagonist serves an adaptive-protective function, such that the limitation of movement promotes healing and protects the injury site from further injury.

\section{Sensory-Motor Integration}

The motor dysfunction in a clinical context appears to be independent of the tissue in which the nociceptive input arises. For example, reduction of bite force occurs in post-operative pain following extraction of wisdom teeth 
and in clinical situations of craniofacial myalgia (Helkimo et al., 1975; High et al., 1988). This can be explained by the fact that trigeminal neurons receive convergent inputs from skin, mucosa, muscle, bone, blood vessels, and teeth. Such input has also been shown to come from both sides of the head and the upper neck (Sessle et al., 1986; Dallel et al., 1990). The fact that unilateral pain has bilateral jaw motor effects can be due to the projections of trigeminal interneurons to both ipsilateral and contralateral trigeminal motor nuclei (Moore and Appenteng, 1990; Donga and Lund, 1991).

The integration of noxious input into jaw motor behaviors seems to occur, to a large part, in the brainstem. Brainstem interneurons have been shown to control temporal, spatial, and quantitative aspects of jaw muscle activity during natural orofacial behaviors (Westberg et al., 1995a,b). This is further supported by experiments in decerebrate animals in which the motor output in the presence of noxious stimulation resembles the behavior of awake humans in pain. In decerebrate rabbits, heavy pressure on the periosteum of the zygoma reduces the frequency, amplitude, and mandibular velocities in mastication evoked by the electrical stimulation of the corticobulbar tract (Schwartz and Lund, 1995). A similar response was observed with the same experimental paradigm used during the infusion of hypertonic saline into the masseter muscle at rates that have been shown to cause pain in humans (Westberg et al., 1997). For noxious input arising in parts other than the craniofacial complex, the corresponding mechanisms are assumed to occur at the level of the spinal cord.

Groundbreaking work by Lund's research team provides further indications regarding the integration of nociceptive input into the motor system. Because the frequency of fictive masticatory movements in the decerebrate rabbit is reduced during noxious stimulation (Schwartz and Lund, 1995; Westberg et al., 1997), projection of nociceptive input on neurons located in the midline of the reticular formation is assumed, since this area has been shown to be critical to the generation of the masticatory rhythm (Nozaki et al., 1986). Neurons in the rostral trigeminal nuclei and adjacent reticular formation that integrate the rhythmic command, sensory input, and input from higher centers shape the bursts of the motoneuron. Some of these neurons change their firing pattern when hypertonic saline is infused into the masseter muscle (Westberg et al., 1995b, 1997).

Peripheral changes in painful muscle could feasibly sensitize or excite large fiber afferents. In addition to the modulation of $\alpha$-motoneurons by nociceptive Group III and Group IV fiber input, the contributions of Groups la and II afferent input from muscle spindles or Group $\mathrm{lb}$ afferent input from Golgi tendon organs exists. One popular speculation in support of the Vicious Cycle Theory was based on the idea that nociceptors would excite fusimotor neurons, which in turn would cause muscle hyperactivity (Solnit and Curnutte, 1988). However, the limited data on this matter do not support the idea that, in the end, an increased $\alpha$-motorneuron drive occurs in response to experimentally induced pain in cats and man. Increased fusimotor drive was not observed in experimentally induced myositis of hindlimb extensors in anesthetized cats (Mense and Skeppar, 1991). In humans with pain induced by hypertonic saline infusion into either the soleus or the tibialis anterior muscle, the amplitude of stretch reflex increases significantly as compared with before pain. However, the H-reflex amplitude is unaffected, and the excitability of $\boldsymbol{\alpha}$-motoneurons remains unchanged (Matre et al., 1998).

\section{Unresolved Issues}

The following experimental finding does not readily fit into the current formulation of the Pain-Adaptation Model and appears, at first impression, to be contradictory to some of the tenets expressed in this review.

Increases in the EMG activity of the jaw muscles occur soon after the injection of mustard oil into the TM joint in anesthetized rats. These increases occur during the first 7 to 8 mins and between approximately 15 and 30 mins following the injection of the small fiber excitant. This motor response is abolished by the pre-administration of local anesthetic into the site in which the noxious stimulation is subsequently applied (Yu et al., 1995), or is attenuated by the intravenous administration of the non-competitive $\mathrm{N}$-methyl-D-aspartate (NMDA) antagonist MK-801 (Yu et al., 1996).

Inhibitory influences constitute the dominant response pattern to peripheral stimulation and activation of central structures. However, the reported increase in EMG activity (Yu et al., 1995) is suggestive of increased resting excitability of $\boldsymbol{\alpha}$-motoneurons of jaw-closing muscles. Because the increase in EMG activity is abolished by the administration of a local anesthetic prior to the inflammatory irritant, the response seems to be dependent on peripheral inflammatory processes linked to pain. Altered descending modulation of ascending nociceptive input in general anesthesia, resulting in an enhanced nociceptive transmission in neural brainstem networks, could be used as an explanation for these excitatory modulatory influences. Given the absence of muscle hyperactivity in awake humans in response to the infusion of hypertonic saline (Stohler et al., 1996), the respective pathway, likely involving the trigeminal (V) subnucleus caudalis and other parts of the trigeminal brainstem complex, must be relatively ineffective in the intact state. Local, time-dependent tissue changes that occur with the accumulation of mast cells, neutrophils, 
and macrophages and the development of edema could be responsible for the reported timing of the phenomenon. Overall, the results presented in this section do not appear to be contradictory to the predictions of the PainAdaptation Model, as the first impression might suggest.

\section{Prolonged Painful Motor Function}

Although not well-documented, it is common knowledge that pain has general effects on the motor behavior of the affected subject that can, in the worst case, involve inactivity of the affected body part. Other motor behaviors linked to pain include guarding, bracing, rubbing, grimacing, and positional shifts (Keefe et al., 1984; Follick et al., 1985; Keefe and Hill, 1985). In the case of the masticatory system, it is feasible to assume that prolonged dietary restrictions due to pain could result in muscle deconditioning that leads to changes in the viscoelastic property of the connective tissue scaffold and/or the contractile elements of muscle.

The question arises whether the consequences of presumed muscle deconditioning could contribute to the clinical presentation in the form of second-order effects, since muscle cells have been shown to regulate their corresponding motoneuron. Indeed, muscle conditioning changes the response properties of related motoneurons to growth factors, influences the state of mature synaptic junctions, and affects the rate by which certain proteins are synthesized at the levels of both neuron and muscle cell. In the periphery, inactivity causes clinically observable muscle atrophy (Grinnell, 1994). Whether prolonged function in pain leads to durable changes in the phenotype of motoneurons and hence their participation in motor circuits to an extent that these effects are not easily reversed remains as a research question.

Higher-order effects beyond the scope of the motor unit need to be entertained as well. Consequences of altered motor function have also been described in CNS locations other than the motoneurons. Immobilization has been shown to reduce mRNA levels for neurotrophins and their high affinity receptors in the brain, especially in the hippocampus (Ueyama et al., 1997). This area has been implicated in memory and learning, and it remains to be seen whether complaints of memory impairment of some patients with disabling widespread pain are linked to this finding

\section{Shift in Treatment Focus}

The interdependence of pain and movement, including the clinical significance of this relationship, has been acknowledged for centuries. The statement found in the Corpus Hippocraticum-"Pain arising in a part of the body will be relieved by rest"-is offered in support of this fact (Hippocrates, 1928). Significant for dentistry were case reports by the otolaryngologist J.B. Costen in 1934 that shifted emphasis on jaw motor dysfunction and the dental occlusion as the cause of craniofacial pain. Although symptoms and signs of motor dysfunction can sometimes be explained by changes in structure, strong evidence suggests that they can also be caused by pain.

Dental practitioners have traditionally favored the assessment of mandibular dysfunction, including the occlusion, over measures of pain. With pain being viewed as a personal experience that is communicated to the clinician in verbal and non-verbal terms, powerful signs of motor and affective dysfunction tend to overshadow the more subtle pain complaint. Motor symptoms include limitations of movement, muscle stiffness, lack of sufficient muscle strength, postural abnormality, and concerns about mandibular posture that are often expressed in the form of perceived 'shifts of the bite' or as 'teeth not fitting together properly'. Given the dominance of the motor symptoms and signs that are often very troublesome to the patient, it does not come as a surprise that many clinicians view these signs as the cause of pain. A plethora of treatments available to the dentist to intervene at the structural level (occlusal appliances, occlusal adjustments, orthodontics, prosthodontic reconstruction, orthognathic surgery) further favors the view of simple mechanical impediments as the cause of pain and its persistence.

Despite reports of success rates of 70 to $90 \%$ with prevailing treatments, failure of the traditional treatment paradigms is exemplified by the fact that $47 \%$ of subjects appearing in a tertiary care environment were barely satisfied, dissatisfied, or very dissatisfied with treatments after having been searching for cures from, on average, 4.9 prior providers (Turp et al., 1998b). Because of the understanding gained in recent years that pain can cause abnormalities in motor function, including many of the symptoms and signs of patients with craniofacial pain (Lund and Sessle, 1994), significant benefit is to be expected from better measures to control persistent pain itself.

Even an altered structural relationship can be attributed to the effect of pain. As an example, the most posterior position from which lateral mandibular movements can be performed is located more anteriorly in experimental pain than in the absence of pain. Subjects also acknowledge a change in their dental occlusion as a consequence of pain in the masticatory system (Obrez and Stohler, 1996). The reduced output of jaw closers in painful concentric work could also account for the smaller number of antagonistic tooth contacts in pain, since biting pressures have been shown significantly to affect 
contacts between opposing teeth (Riise, 1982). There is also evidence that other motor signs, such as the reduction in amplitude of maximum protrusion and laterotrusion, are the immediate consequence of pain and not the motor dysfunction that produces pain lobrez and Stohler, 1996).

With the improved understanding of the relationship between pain and motor function, including the inappropriateness of many clinical assumptions, we are also witnessing the emergence of a new body of literature that opens the door to exciting therapeutic opportunities. With increasing evidence supporting the view that pain causes changes in motor function, the treatment target is shifting from structural modifications to the control of persistent pain itself. This shift in emphasis is paralleled by farreaching discoveries in the field of pain that identify opportunities for novel treatments. This is welcome news for a patient suffering from persistent craniofacial pain of musculoskeletal origin. On the other hand, it should be understood that, in subsets of patients with failed TM joint implants, life-threatening situations could arise regardiess of pain. In many such patients, treatment has also caused irreversible damage to their dental occlusion that calls for structural correction regardless of pain. Obviously, the benefit of the control of persistent pain in these subsets of patients is of limited meaning.

\section{Novel Treatment Targets}

It is now recognized that prolonged pain fiber activity induces peripheral and central changes that have profound consequences on the processing of a range of stimuli and not just pain. Peripherally, thin afferent fibers are implicated in inducing a state of inflammation that is attributed to the release of neuropeptides from the excited afferent terminals and the release of catecholamines from post-ganglionic sympathetic efferent neurons (Levine et al., 1985). Mediators of the neurogenic inflammation include a few short neuropeptides, such as substance $\mathrm{P}$ (SP, also known as NK1) and neurokinin A (NK2), somatostatin (SIH), calcitonin gene-related peptide (CGRP), and the vasoactive intestinal peptide (VIP). When released peripherally, SP has been shown to stimulate the proliferation and differentiation of activated lymphocytes, to induce the synthesis of immunoglobulins, and to cause mast cell degranulation. vasodilatation, changes in vascular permeability, plasma extravasation, and peripheral nerve sensitization are local consequences, and some of these events appear to be tissue-dependent, stimulus-specific, and age- and sex-dependent (Levine and Taiwo, 1994). Endogenous opioid peptides that are synthesized by inflammatory cells increase the complexity of possible interactions and indicate mechanisms by which anti-nociception can be exerted in peripheral tissue (Schafer et al., 1994).

Newer data specifically implicate the nerve growth factor (NGF) as a major peripheral contributor in inflammatory pain (Woolf et al., 1994; Levi-Montalcini et al., 1995). First hints of its potential significance to craniofacial pain came from a phase I clinical trial that included the subcutaneous and intravenous injection of recombinant human NGF (rhNGF) at doses ranging up to $1 \mu \mathrm{g} / \mathrm{kg}$. The healthy human volunteers developed pain in the bulbar, jaw, and truncal musculature and described the observation as 'overuse' pain. Most subjects receiving rhNGF subcutaneously experienced hyperalgesia at the injection site that lasted up to 49 days. Diffuse myalgia developed about 60-90 minutes after intravenous administration. Pain tended to worsen with chewing, swallowing, and eye movements. The duration and severity of these myalgias varied in a dose-dependent manner, with women showing greater susceptibility to NGF-induced myalgia than men (Petty et al., 1994). The significance of NGF is further amplified by the finding that primary sensory neurons tend to develop novel mechanosensitivity in the presence of NGF (Dmitrieva and McMahon, 1996). On the other hand, the administration of synthetic trkA immunoglobulin G blocks the effects of NGF, and NGF antiserum, injected one $\mathrm{hr}$ before the induction of inflammation by intraplantar administration of complete Freund's adjuvant, has been shown to attenuate touchand-pinch responses (McMahon et al., 1995; Ma and Woolf, 1997). This is potentially important, because mast cells, known to synthesize, store, and release NGF (Leon et al. 1994), have been loosely linked to pain following experimental tooth-grinding. When compared with baseline, an increase of degranulating mast cells was observed in biopsies that were harvested 20 hrs after experimental tooth-grinding for 25 mins (Christensen, 1978). Because more women than men are affected by persistent pain conditions, including the TM disorders, emerging data that establish a link between NGF and estrogen could be a key in further elucidating the pathogenesis of these conditions (Stohler, 1997).

Effects in the central nervous system parallel the peripheral changes. Substance $P$, released in response to noxious stimulation, is found in high concentrations in the dorsal horn in locations where unmyelinated afferents terminate on second-order neurons (Hokfelt et al., 1975; Schaible et al., 1990). Inflammation in the receptive field appears to be a significant factor because, in the absence of inflammation, internalization of the receptor/ligand (NK-1/SP) complex is found in only $22 \%$ of lamina I neurons following a five-second noxious mechanical stimulus in normal rats. In contrast, a nearmaximal internalization of the NK-1/SP complex (98\%) was found in the presence of inflammation, with significant changes also occurring in laminae II-IV and rostro- 
caudally as well (Abbadie et al., 1997). Besides the neuronal barrage and the activation of second-messenger systems by SP, central neural processing is further modulated by the effects of excitatory amino acids (glutamate, aspartate) and changes in gene expression, such as the gene c-fos and its protein. Together, peripheral and central effects result in sensory changes that are clinically observable and are referred to as hyperalgesia and allodynia. The extra-territorial sensory abnormalities have been linked to the altered properties of the involved central neurons (Meyer and Campbell, 1981; LaMotte et al., 1992; Törebjörk et al., 1992; Sang et al., 1996).

Recent studies have also identified new treatment targets that hold great promise. Attenuation of the effects of noxious stimuli and mechanical and thermal hyperalgesia was observed following the infusion into the spinal cord of a conjugate of substance $\mathrm{P}$ and the ribosome-inactivating protein saporin, with the reduction of the response being attributed to the cytotoxic effects on lamina I neurons (Mantyh et al., 1997). The fact that activation of the NMDA ( $N$-methyl-D-aspartate)type glutamate receptor causes release of substance $\mathrm{P}$ (Liu et al., 1997), the demonstration that altered properties of nociceptive neurons involve NMDA receptor mechanisms (Chiang et al., 1997), and that hypoactivity of the spinal cannabinoid system results in an NMDAdependent hyperalgesia (Richardson et al., 1998) provide powerful clues for the discovery of new drugs. Great expectations are also attached to the possibility of inhibitors of protein kinase $C$ gamma (PKCgamma) to facilitate the selective control of persistent pain. Mutant mice lacking the protein kinase $\mathrm{C}$ gamma (PKCgamma) almost completely fail to develop persistent neuropathic pain after partial sciatic nerve section. However, these animals exhibit normal responsivity to acute pain stimuli (Malmberg et al., 1997). It is reasonable to project that novel types of treatments, such as selective inhibitors of PKCgamma, will likely have a profound impact on the treatment of persistent pain and its effect on motor function in the not-too-distant future.

\section{Acknowledgments}

This project was supported by the following grants from the National Institute of Dental and Craniofacial Research: ROI DE8606-10, "Pain-modulated jaw motor function" (CSS), and ROI DE1 2059-03, "Pathogenesis of TMD myalgia symptoms" (CSS).

\section{REFERENCES}

Abbadie C, Trafton J, Liu H, Mantyh PW, Basbaum AI (1997). Inflammation increases the distribution of dorsal horn neurons that internalize the neurokinin-1 receptor in response to noxious and non-noxious stimulation. J Neurosci 17:8049-8060.

Abraham WM (1977). Factors in delayed muscle soreness. Med Sci Sports 9:11-20.

Ahern DK, Follick MJ, Council JR, Laser-Wolston N, Litchman H (1988). Comparison of lumbar paravertebral EMG patterns in chronic low back pain patients and non-patient controls. Pain 34:153-160.

Alston W, Carlson KE, Feldman Dl, Grimm Z, Gerontinos $E$ (1966). A quantitative study of muscle factors in the chronic low back syndrome. I Am Geriatr Soc 14:10411047.

Ashton-Miller IA, McGlashen KM, Herzenberg IE, Stohler CS (1990). Cervical muscle myoelectric response to acute experimental sternocleidomastoid pain. Spine 15:1006-1012.

Asmussen E (1956). Observations on experimental muscle soreness. Acta Rheumatol Scand 209:109-116.

Backman E, Bengtsson A, Bengtsson M, Lennmarken C, Henriksson KG (1988). Skeletal muscle function in primary fibromyalgia. Effect of regional sympathetic blockade with guanethidine. Acta Neurol Scand 77:187191.

Bansevicius D, Westgaard RH, Jensen C (1997). Mental stress of long duration: EMG activity, perceived tension, fatigue, and pain development in pain-free subjects. Headache 37:499-510.

Barton PM. Hayes KC (1996). Neck flexor muscle strength, efficiency, and relaxation times in normal subjects and subjects with unilateral neck pain and headache. Arch Phys Med Rehabil 77:680-687.

Bengtsson A, Henriksson KG, Larsson I (1986a). Muscle biopsy in primary fibromyalgia. Light-microscopical and histochemical findings. Scand I Rheumatol 15:1-6.

Bengtsson A, Henriksson KG, Jorfeldt L, Kagedal B, Lennmarken C, Lindstrom F (1986b). Primary fibromyalgia. A clinical and laboratory study of 55 patients. Scand J Rheumatol 15:340-347.

Carraro II. Caffesse RG (1978). Effect of occlusal splints on TMJ symptomatology. J Prosthet Dent 40:563-566.

Chiang CY, Hu JW, Sessle BJ (1997). NMDA receptor involvement in neuroplastic changes induced by neonatal capsaicin treatment in trigeminal nociceptive neurons. J Neurophysiol 78:2799-2803.

Christensen LV (1978). Mast cells in masseter muscle in experimental bruxism in man. I Oral Rehabil 5:23-27.

Collins GA, Cohen M], Naliboff BD, Schandler SL (1982). Comparative analysis of paraspinal and frontalis EMG, heart rate and skin conductance in chronic low back pain patients and normals to various postures and stress. Scand J Rehabil Med 14:39-46.

Costen JB (1934). A syndrome of ear and sinus symptoms dependent upon disturbed function of the temporomandibular joint. Ann Otol Rhinol Laryngol 43:1-15. 
Craig KD, Patrick CJ (1985). Facial expression during induced pain. J Pers Soc Psychol 48:1080-1091.

Dahlstrom L, Carlsson SG, Gale EN, Jansson TG (1985). Stress-induced muscular activity in mandibular dysfunction: effects of biofeedback training. I Behav Med 8:191-200.

Dallel R, Raboisson P, Woda A, Sessle BI (1990). Properties of nociceptive and non-nociceptive neurons in trigeminal subnucleus oralis of the rat. Brain Res 521:95-106.

Dao TT, Lund IP, Lavigne G) (1994). Pain responses to experimental chewing in myofascial pain patients. I Dent Res 73:1163-1167.

Darwin C (1873). The expression of the emotions in man and animals. New York: D. Appleton and Company.

de Ceballos ML, Baker M, Rose S, Jenner P, Marsden CD (1986). Do enkephalins in basal ganglia mediate a physiological motor rest mechanism? Mov Disord 1:223-233.

Dmitrieva N, McMahon SB (1996). Sensitisation of visceral afferents by nerve growth factor in the adult rat. Pain 66:87-97.

Dohrmann RI. Laskin DM (1978). An evaluation of electromyographic biofeedback in the treatment of myofascial pain-dysfunction syndrome. I Am Dent Assoc 96:656-662.

Donga R, Lund IP (1991). Discharge patterns of trigeminal commissural last-order interneurons during fictive mastication in the rabbit. I Neurophysiol 66:15641578.

Dworkin SF, LeResche L (1992). Research diagnostic criteria for temporomandibular disorders: review, criteria, examinations and specifications, critique. I Craniomandib Disord 6:301-355.

Farmand M, Rowlerson A (1985). IMasseter muscle hypertrophy. A histochemical study|. Dtsch Z Mund Kiefer Gesichtschir 9: 143-148.

Follick MI, Ahern DK, Aberger EW (1985). Development of an audiovisual taxonomy of pain behavior: reliability and discriminant validity. Health Psychol 4:555-568.

Geisser ME, Robinson ME, Richardson C (1995). A time series analysis of the relationship between ambulatory EMG, pain, and stress in chronic low back pain. Biofeedback \& Self Regulation 20:339-355.

Goldreich H, Gazit E, Lieberman MA, Rugh JD (1994). The effect of pain from orthodontic arch wire adjustment on masseter muscle electromyographic activity. Am J Orthod Dentofac Orthop 106:365-370.

Graven-Nielsen T, Svensson P, Arendt-Nielsen L (1997). Effects of experimental muscle pain on muscle activity and co-ordination during static and dynamic motor function. Electroencephalog Clin Neurophysiol 105:156164.

Greene CS, Laskin DM (1974). Long-term evaluation of conservative treatment for myofascial pain-dysfunction syndrome. J Am Dent Assoc 89:1365-1368.

Greene CS, Laskin DM (1983). Long-term evaluation of treatment for myofascial pain-dysfunction syndrome: a comparative analysis. J Am Dent Assoc 107:235-238.

Grinnell AD (1994). Trophic interaction between nerve and muscle. In: Myology. 2nd ed. Engel AG, FranziniArmstrong C, editors. New York, NY: McGraw-Hill, pp. 303-332.

Hagberg C (1991). General musculoskeletal complaints in a group of patients with craniomandibular disorders (CMD). A case control study. Swed Dent J 15:179-185.

Hawley DJ, Wolfe F (1991). Pain, disability, and pain/disability relationships in seven rheumatic disorders: a study of 1,522 patients. I Rheumatol 18:1552-1557.

Hazard RG, Haugh LD, Green PA, Iones PL (1994). Chronic low back pain: the relationship between patient satisfaction and pain, impairment, and disability outcomes. Spine 19:881-887.

Helkimo E, Carlsson GE, Yehuda C (1975). Bite force in patients with functional disturbances of the masticatory system. I Oral Rehabil 2:397-406.

Helkimo E, Carlsson GE, Helkimo M (1977). Bite force and state of dentition. Acta Odontol Scand 35:297-303.

Heloe B, Heiberg AN (1980). A follow-up study of a group of female patients with myofascial pain-dysfunction syndrome. Acta Odontol Scand 38:129-134.

High AS, MacGregor AI, Tomlinson GE, Salkouskis PM (1988). A gnathodynanometer as an objective means of pain assessment following wisdom tooth removal. Br I Oral Maxillofac Surg 26:284-291.

Hippocrates (1928). Corpus Hippocraticum. Cambridge, MA: Harvard University Press.

Hokfelt T, Kellerth JO, Nilsson G, Pernow B (1975). Substance $\mathrm{P}$ : localization in the central nervous system and in some primary sensory neurons. Science 190:889-890.

Hough $\mathrm{T}(1902)$. Ergographic studies in muscle soreness. Am J Physiol 7:76-92.

Howell IN, Chila AG, Ford G, David D, Gates T (1985). An electromyographic study of elbow motion during postexercise muscle soreness. I Appl Physiol 58:1713-1718.

Howell JN, Chleboun G, Conatser R (1993). Muscle stiffness, strength loss, swelling and soreness following exercise-induced injury in humans. I Physiol (Lond) 464: 183-196

Hoyt WH, Hunt HHI, De Pauw MA, Bard D, Shaffer F, Passias IN, et al. (1981). Electromyographic assessment of chronic low-back pain syndrome. I Am Osteopath Assoc 80:728-730.

Huggins KH, Dworkin SF, Saunders K, Von Korff $M$, Barlow W (1996). Five-year course for temporomandibular disorders using RDC/TMD (abstract). I Dent Res 75(Spec Iss): 352 
Hurwitz DE, Hulet $\mathrm{CH}$, Andriacchi TP, Rosenberg AG, Galante IO (1997). Gait compensations in patients with osteoarthritis of the hip and their relationship to pain and passive hip motion. J Orthopaed Res 15:629-635.

Jacobsen S, Danneskiold-Samsoe B (1987). Isometric and isokinetic muscle strength in patients with fibrositis syndrome. New characteristics for a difficult definable category of patients. Scand I Rheumatol 16:61-65.

Iones DA, Newham DI, Clarkson PM (1987). Skeletal muscle stiffness and pain following eccentric exercise of the elbow flexors. Pain 30:233-242.

Iones DA, Newham DJ, Torgan C (1989). Mechanical influences on long-lasting human muscle fatigue and delayed-onset pain. I Physiol (Lond) 412:415-427.

Keefe FJ, Hill RW (1985). An objective approach to quantifying pain behavior and gait patterns in low back pain patients. Pain 21:153-161.

Keefe Fl, Wilkins RH, Cook WA (1984). Direct observation of pain behavior in low back pain patients during physical examination. Pain 20:59-68.

LaMotte RH, Lundberg LE, Torebjork HE (1992). Pain, hyperalgesia and activity in nociceptive $C$ units in humans after intradermal injection of capsaicin. I Physiol (Lond) 448:749-764.

Larsson SE, Bengtsson A, Bodegard L, Henriksson KG, Larsson I (1988). Muscle changes in work-related chronic myalgia. Acta Orthop Scand 59:552-556.

Leon A, Buriani A, Dal Toso R, Fabris M, Romanello S, Aloe L, et al. (1994). Mast cells synthesize, store, and release nerve growth factor. Proc Natl Acad Sci USA 91:3739-3743.

LeResche L, Dworkin SF (1984). Facial expression accompanying pain. Soc Sci Med 19:1325-1330.

LeResche L, Dworkin SF (1988). Facial expressions of pain and emotions in chronic TMD patients. Pain 35:71-78.

Levi-Montalcini R, Dal Toso R, della Valle F, Skaper SD, Leon A (1995). Update of the NGF saga. I Neurol Sci 130:119-127.

Levine J, Taiwo Y (1994). Inflammatory pain. In: Textbook of pain. 3rd ed. Wall PD, Melzack R, editors. New York: Churchill Livingstone, pp 45-56.

Levine JD, Moskowitz MA, Basbaum AI (1985). The contribution of neurogenic inflammation in experimental arthritis. I Immunol 135:843s-847s.

Lindman $R$, Hagberg $M$, Angqvist $K A$, Soderlund $K$, Hultman E, Thornell LE (1991). Changes in muscle morphology in chronic trapezius myalgia. Scand J Work Environ Health 17:347-355.

Liu H, Mantyh PW, Basbaum AI (1997). NMDA-receptor regulation of substance $P$ release from primary afferent nociceptors. Nature 386:721-724

Lund JP, Sessle BI (1994). Neurophysiological mechanisms. In: Temporomandibular joint and masticatory muscle disorders. 2nd ed. Zarb GA, Carlsson GE, Sessle B], Mohl ND, editors. Copenhagen: Munksgaard, pp. 188-207.

Lund IP, Stohler CS (1994). Effect of pain on muscular activity in temporomandibular disorders and related conditions. In: Craniofacial growth series. Vol. 29. Biological and psychological aspects of orofacial pain. Stohler CS, Carlson DS, editors. Ann Arbor, MI: Center for Human Growth and Development, The University of Michigan, pp. 75-91.

Lund JP, Donga R, Widmer CG, Stohler CS (1991). The pain-adaptation model: a discussion of the relationship between chronic musculoskeletal pain and motor activity. Can I Physiol Pharmacol 69:683-694.

Lund IP, Stohler CS, Widmer CG (1993). The relationship between pain and muscle activity in fibromyalgia and similar conditions. In: Progress in fibromyalgia and myofascial pain. Voeroy $H$, Merskey $H$, editors. Amsterdam: Elsevier.

Lund JP, Clavelou P, Westberg KG, Schwartz G (1995) Reaction paper to Chapters 1-4. In: Temporomandibular disorders and related pain conditions. Sessle BJ, Bryant PS, Dionne RA, editors. Seattle, WA: International Association for the Study of Pain, pp. 71-76.

Ma OP, Woolf CJ (1997). The progressive tactile hyperal gesia induced by peripheral inflammation is nerve growth factor dependent. Neuroreport 8:807-810.

Majewski RF, Gale EN (1984). Electromyographic activity of anterior temporal area pain patients and non-pain subjects. J Dent Res 63:1228-1231.

Malmberg AB, Chen C, Tonegawa S, Basbaum AI (1997). Preserved acute pain and reduced neuropathic pain in mice lacking PKCgamma [see comments]. Science 278:279-283.

Mantyh PW, Rogers SD, Honore P, Allen BI, Ghilardi JR, Li J, et al. (1997). Inhibition of hyperalgesia by ablation of lamina I spinal neurons expressing the substance P receptor. Science 278:275-279.

Matre DA, Sinkjaer T, Svensson P, Arendt-Nielsen L (1998). Experimental muscle pain increases the human stretch reflex. Pain 75:331-339.

McMahon SB, Bennett DL, Priestley IV, Shelton DL (1995). The biological effects of endogenous nerve growth factor on adult sensory neurons revealed by a trkA-IgG fusion molecule [see comments]. Nat Med 1:774-780.

Mense S, Skeppar P (1991). Discharge behaviour of feline gamma-motoneurones following induction of an artificial myositis. Pain 46:201-210.

Meyer RA, Campbell IN (1981). Myelinated nociceptive afferents account for the hyperalgesia that follows a burn to the hand. Science 213:1527-1529.

Moller E, Sheikholeslam A, Lous I (1984). Response of 
elevator activity during mastication to treatment of functional disorders. Scand I Dent Res 92:64-83.

Moore J, Appenteng K (1990). The membrane properties and firing characteristics of rat jaw-elevator motoneurones. I Physiol (Lond) 423:137-153.

Nel H (1978). Myofascial pain-dysfunction syndrome. I Prosthet Dent 40:438-441.

Newham DI, Mills KR, Quigley BM, Edwards RH (1983a). Pain and fatigue after concentric and eccentric muscle contractions. Clin Sci 64:55-62.

Newham DI, McPhail G, Mills KR, Edwards RH (1983b). Ultrastructural changes after concentric and eccentric contractions of human muscle. J Neurol Sci 61:109-122.

Nice DA, Riddle DL, Lamb RL, Mayhew TP, Rucker K (1992) Intertester reliability of judgments of the presence of trigger points in patients with low back pain. Arch Phys Med Rehabil 73:893-898.

Nosaka K, Clarkson PM (1996). Changes in indicators of inflammation after eccentric exercise of the elbow flexors. Med Sci Sports Exerc 28:953-961.

Nouwen A, Bush C (1984). The relationship between paraspinal EMG and chronic low back pain. Pain 20:109-123.

Nozaki S, Iriki A, Nakamura Y (1986). Localization of central rhythm generator involved in cortically induced rhythmical masticatory jaw-opening movement in the guinea pig. I Neurophysiol 55:806-825.

Obrez A, Stohler CS (1996). Jaw muscle pain and its effect on gothic arch tracings. J Prosthet Dent 75:393-398.

Oliveau D, Willmuth R (1979). Facial muscle electromyography in depressed and nondepressed hospitalized subjects: a partial replication. Am J Psychiatry 136:548550 .

Petty BG, Cornblath DR, Adornato BT, Chaudhry V, Flexner C, Wachsman M, et al. (1994). The effect of systemically administered recombinant human nerve growth factor in healthy human subjects. Ann Neurol 36:244-246.

Ramfiord SP, Ash MM (1983). Occlusion. 3rd ed. Philadelphia: W.B. Saunders.

Richardson ID, Aanonsen L, Hargreaves KM (1998). Hypoactivity of the spinal cannabinoid system results in NMDA-dependent hyperalgesia. J Neurosci 18:451-457.

Riise C (1982). A clinical study of the number of occlusal tooth contacts in the intercuspal position at light and hard pressure in adults. J Oral Rehabil 9:469-477.

Rugh ID, Montgomery GT (1987). Physiological reactions of patients with TM disorders vs symptom-free controls on a physical stress task. I Craniomandib Disord 1 243-250.

Sang CN, Gracely RH, Max MB, Bennett GI (1996). Capsaicin-evoked mechanical allodynia and hyperalgesia cross nerve territories. Evidence for a central mechanism [see comments]. Anesthesiology 85:491-496.
Schafer M. Carter L, Stein C (1994). Interleukin 1 beta and corticotropin-releasing factor inhibit pain by releasing opioids from immune cells in inflamed tissue. Proc Natl Acad Sci USA 91:4219-4223.

Schaible HG, Jarrott B, Hope PI, Duggan AW (1990). Release of immunoreactive substance $P$ in the spinal cord during development of acute arthritis in the knee joint of the cat: a study with antibody microprobes. Brain Res 529:214-223.

Schoenen I, Gerard P, De Pasqua V, Sianard-Gainko I (1991). Multiple clinical and paraclinical analyses of chronic tension-type headache associated or unassociated with disorder of pericranial muscles. Cephalalgia 11:135-139.

Schwartz G, Lund IP (1995). Modification of rhythmical jaw movements by noxious pressure applied to the periosteum of the zygoma in decerebrate rabbits. Pain 63:153-161.

Schwartz G, Stohler CS, Lund JP (1993). An animal model to study the effects of pain on mandibular function. I Orofac Pain 7:107-107.

Sessle BJ, Hu IW, Amano N, Zhong G (1986). Convergence of cutaneous, tooth pulp, visceral, neck and muscle afferents onto nociceptive and non-nociceptive neurones in trigeminal subnucleus caudalis (medullary dorsal horn) and its implications for referred pain. Pain 27:219-235

Sherman RA (1985). Relationships between jaw pain and jaw muscle contraction level: underlying factors and treatment effectiveness. J Prosthet Dent 54:114-118.

Simons DG, Mense S (1998). Understanding and measurement of muscle tone as related to clinical muscle pain |review|. Pain 75:1-17.

Solnit A, Curnutte DC (1988). Occlusal correction: principles and practice. Chicago: Quintessence, pp. 1-413.

Stohler CS (1997). Masticatory myalgias: emphasis on the nerve growth factor-estrogen link. Pain Forum 6:176-180.

Stohler C, Yamada Y, Ash MM Ir (1985a). Antagonistic muscle stiffness and associated reflex behaviour in the pain-dysfunctional state. Schweiz Monatsschr Zannmed 95:719-726.

Stohler CS, Yamada Y, Ash MM Ir (1985b). Non-linear amplification of electromyographic signals with particular application to human chewing. Arch Oral Biol 30:217-219.

Stohler CS, Ashton-Miller IA, Carlson DS (1988). The effects of pain from the mandibular joint and muscles on masticatory motor behaviour in man. Arch Oral Biol 33:175-182.

Stohler CS, Zhang X, Lund IP (1996). The effect of experimental jaw muscle pain on postural muscle activity. Pain 66:215-221.

Sutton EP, Belar CD (1982). Tension headache patients 
versus controls: a study of EMG parameters. Headache 22:133-136.

Svensson P, Arendt-Nielsen L, Houe L (1996). Sensory-motor interactions of human experimental unilateral jaw muscle pain: a quantitative analysis. Pain 64:241-249.

Tesio L, Granger CV, Fiedler RC (1997). A unidimensional pain/disability measure for low-back pain syndromes. Pain 69:269-278.

Thorstensson A, Arvidson A (1982). Trunk muscle strength and low back pain. Scand I Rehabil Med 14:69-75.

Torebjork HE, Lundberg LE, LaMotte RH (1992). Central changes in processing of mechanoreceptive input in capsaicin-induced secondary hyperalgesia in humans. I Physiol (Lond) 448:765-780.

Travell IG, Rinzler S, Herman M (1942). Pain and disability of the shoulder and arm. Treatment by intramuscular infiltration with procaine hydrochloride. I Am Med Assoc 120:417-422.

Triano JI. Schultz AB (1987). Correlation of objective measure of trunk motion and muscle function with lowback disability ratings. Spine 12:561-565.

Turk DC (1996). Biopsychosocial perspective of chronic pain. In: Psychological approaches to pain management. A practitioner's handbook. Gatchel RI, Turk DC, editors. New York: The Guilford Press, pp. 3-32.

Turp IC, Kowalski CI, Stohler CS (1997). Greater disability with increased pain involvement, pain intensity and depressive preoccupation. Eur ] Pain 1:271-277.

Turp IC, Kowalski Cl, O'Leary TI, Stohler CS (1998a). Pain maps from facial pain patients indicate a broad pain geography. J Dent Res 77:1465-1472.

Turp IC, Kowalski CI, Stohler CS (1998b). Treatment-seeking patterns of facial pain patients: many possibilities, limited satisfaction. J Orofac Pain 12:61-66.

Ueyama T, Kawai Y, Nemoto $K$, Sekimoto $M$, Tone $S$, Senba $E$ (1997). Immobilization stress reduced the expression of neurotrophins and their receptors in the rat brain. Neurosci Res 28:103-110.

Veerasarn P, Stohler CS (1992). The effect of experimental muscle pain on the background electrical brain activity. Pain 49:349-360.

Von Korff M, Ormel I, Keefe F], Dworkin SF (1992).
Grading the severity of chronic pain. Pain 50:133-149. Westberg KG. Clavelou P, Schwartz G, Lund IP, Valiquette $C$ (1995a). Effects of deep muscle pain on trigeminal motoneurons and interneurons during fictive mastication (abstract). Soc Neurosci Abst 21:1639.

Westberg KG, Olsson KA, Lund IP, Clavelou P (1995b). Premotoneurones in the oral nucleus of the spinal trigeminal tract-functional characteristics. In: Brain and oral function. Morimoto T, Matsuya T, Takada K, editors. Amsterdam: Elsevier, pp. 87-97.

Westberg KG, Clavelou P, Schwartz G, Lund JP (1997). Effects of chemical stimulation of masseter muscle nociceptors on trigeminal motoneuron and interneuron activities during fictive mastication in the rabbit. Pain 73:295-308.

Wolfe F, Simons DG, Fricton I, Bennett RM, Goldenberg DL, Gerwin R, et al. (1992). The fibromyalgia and myofascial pain syndromes: a preliminary study of tender points and trigger points in persons with fibromyalgia, myofascial pain syndrome and no disease. J Rheumatol 19:944-951.

Woolf CI, Safieh-Garabedian B, Ma OP, Crilly P, Winter J (1994). Nerve growth factor contributes to the generation of inflammatory sensory hypersensitivity. Neuroscience 62:327-331.

Yu XM, Sessle BJ, Vernon H, Hu JW (1995). Effects of inflammatory irritant application to the rat temporomandibular joint on jaw and neck muscle activity. Pain 60: 143-149.

Yu XM, Sessle BJ, Haas DA, Izzo A, Vernon H, Hu JW (1996). Involvement of NMDA receptor mechanisms in jaw electromyographic activity and plasma extrava sation induced by inflammatory irritant application to temporomandibular joint region of rats. Pain 68:169. 178.

Zhang X, Ashton-Miller JA, Stohler CS (1993). A closedloop system for maintaining constant experimental muscle pain in man. IEEE Trans Biomed Eng 40:344352.

Zidar J, Backman E, Bengtsson A, Henriksson KG (1990). Quantitative EMG and muscle tension in painful muscles in fibromyalgia. Pain 40:249-254. 